\title{
Resolution of a refractory severe biliary stricture using a diathermic sheath
}

Endoscopic treatment of postoperative bile duct strictures (BDSs) is safe and effective [1]. However, when the BDS is severe and only the guide wire can be passed through it, stent placement is not possible. We describe a case of refractory, severe postoperative hilar BDS that was successfully treated using a diathermic sheath.

A 47-year-old man was admitted to our department with recurrent cholangitis. He had previously undergone surgical treatment for gallbladder cancer in 2009, which was followed by regular placement of 7-Fr tube stents for BDS, until the stent was removed at the request of the patient, despite the fact that endoscopic retrograde cholangiopancreatography (ERCP) still revealed a BDS. As a result, 17 months later he developed cholangitis. An ERCP following admission revealed severe hilar BDSs ( Fig. 1 a). Although a 0.035-inch guide wire was successfully advanced across the left hepatic BDS ( $\mathbf{F i g . 1} \mathbf{b}$ ), it was not possible to pass a tapered catheter, Soehendra biliary dilation catheter, or stent retriever (Wilson-Cook, WinstonSalem, North Carolina, USA; $\bullet$ Video 1).

It was therefore decided to incise the BDS using a 6-Fr diathermic sheath (CystoGastro-Set; Endo-Flex, Voerde, Germany - Fig.2), which was advanced over the guide wire to the level of the left hepatic BDS ( Fig.3a; Video 1). An incision was made in the BDS using an electrosurgical generator ( $\bullet$ Fig. 3 b, $\bullet$ Video 1 ) and a 5-Fr nasobiliary tube was placed. The patient experienced no serious complications. An ERCP 5 days later revealed resolution of the left hepatic BDS ( Fig.4a), and 7-Fr plastic stents were successfully placed ( $\bullet$ Fig. 4 b).

Diathermic sheaths have been used previously to enlarge the channel between the stomach or duodenum and a pancreatic pseudocyst, the pancreatic duct or the gallbladder [2-5]. To our knowledge, this is the first report of a refractory, severe postoperative BDS successfully treated using a diathermic sheath. Although further study is required, this approach has great potential for selected patients with refractory BDS.
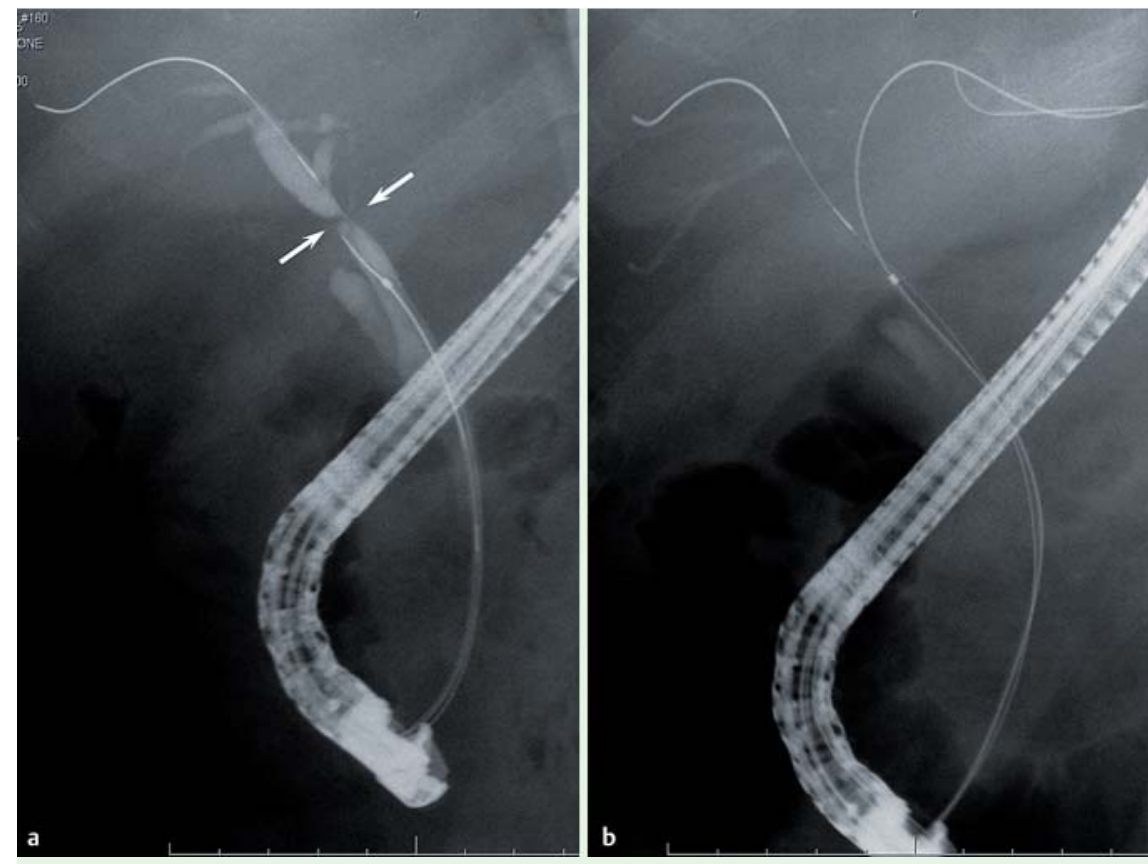

Fig. 1 Radiographic images showing: a a severe hilar bile duct stricture in a 47-year-old man previously treated for gallbladder cancer; $\mathbf{b}$ the hydrophilic, 0.035 -inch guide wire that was successfully advanced across the left hepatic bile duct stricture.

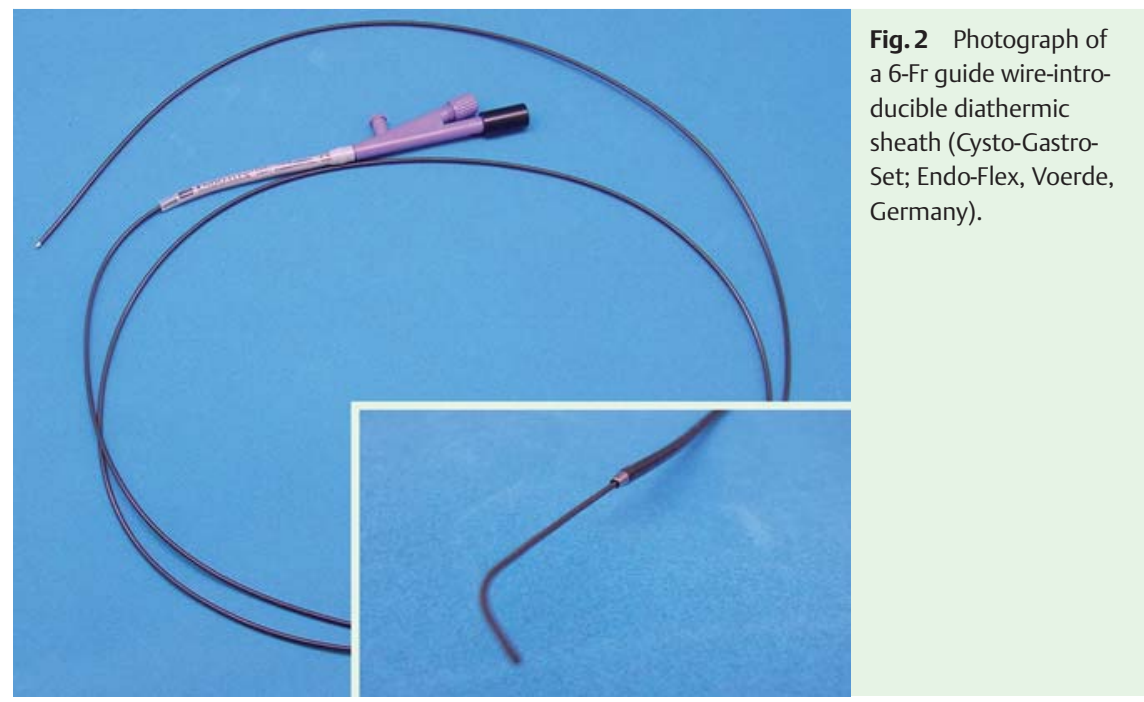

Endoscopy_UCTN_Code_TTT_1AR_2AG

Video 1

Video showing that catheters could not be advanced over the 0.035 -inch guide wire; therefore, a 6-Fr diathermic sheath is advanced to the level of the left hepatic bile duct stricture and an incision is made using an electrosurgical generator.
Competing interests: None 

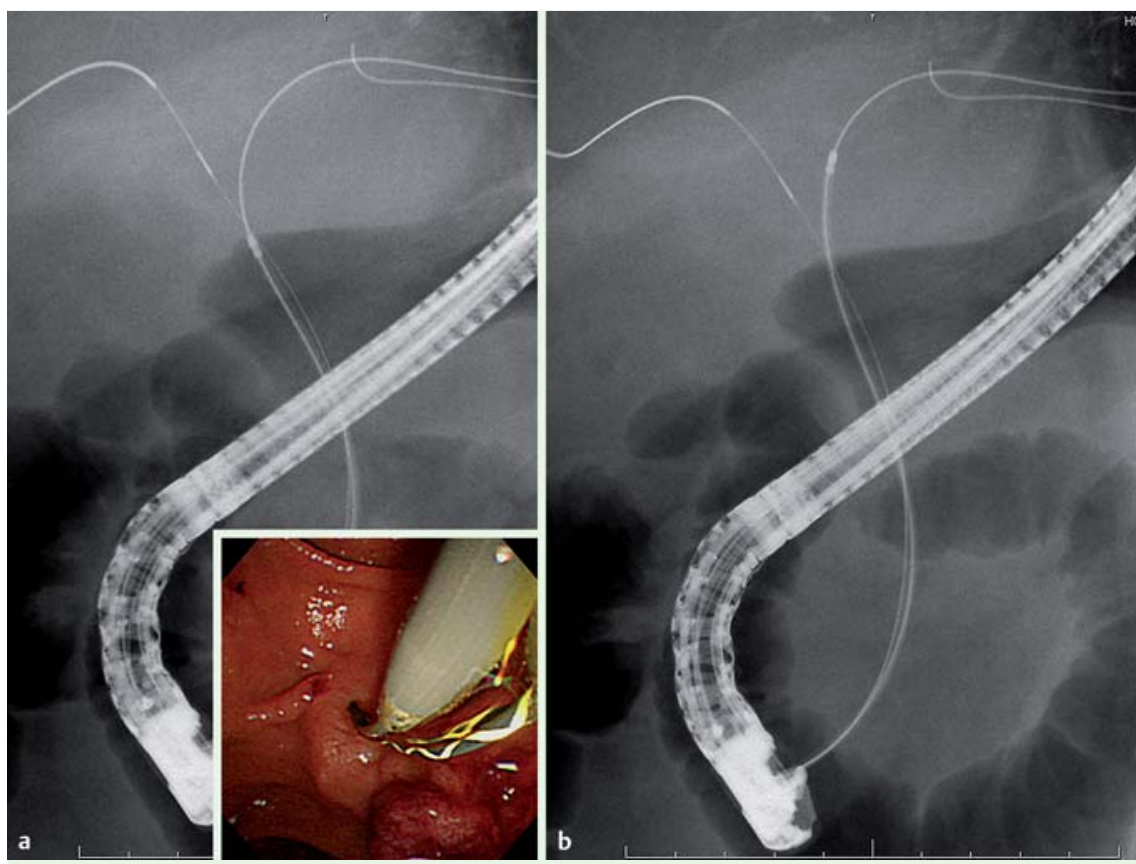

Fig. 3 Radiographic images showing: a the diathermic sheath being advanced over the guide wire to the level of the bile duct stricture (inset: endoscopic view of the diathermic sheath being advanced over the guide wire into the bile duct); $\mathbf{b}$ the diathermic sheath after its passage through the stricture in the left hepatic bile duct.
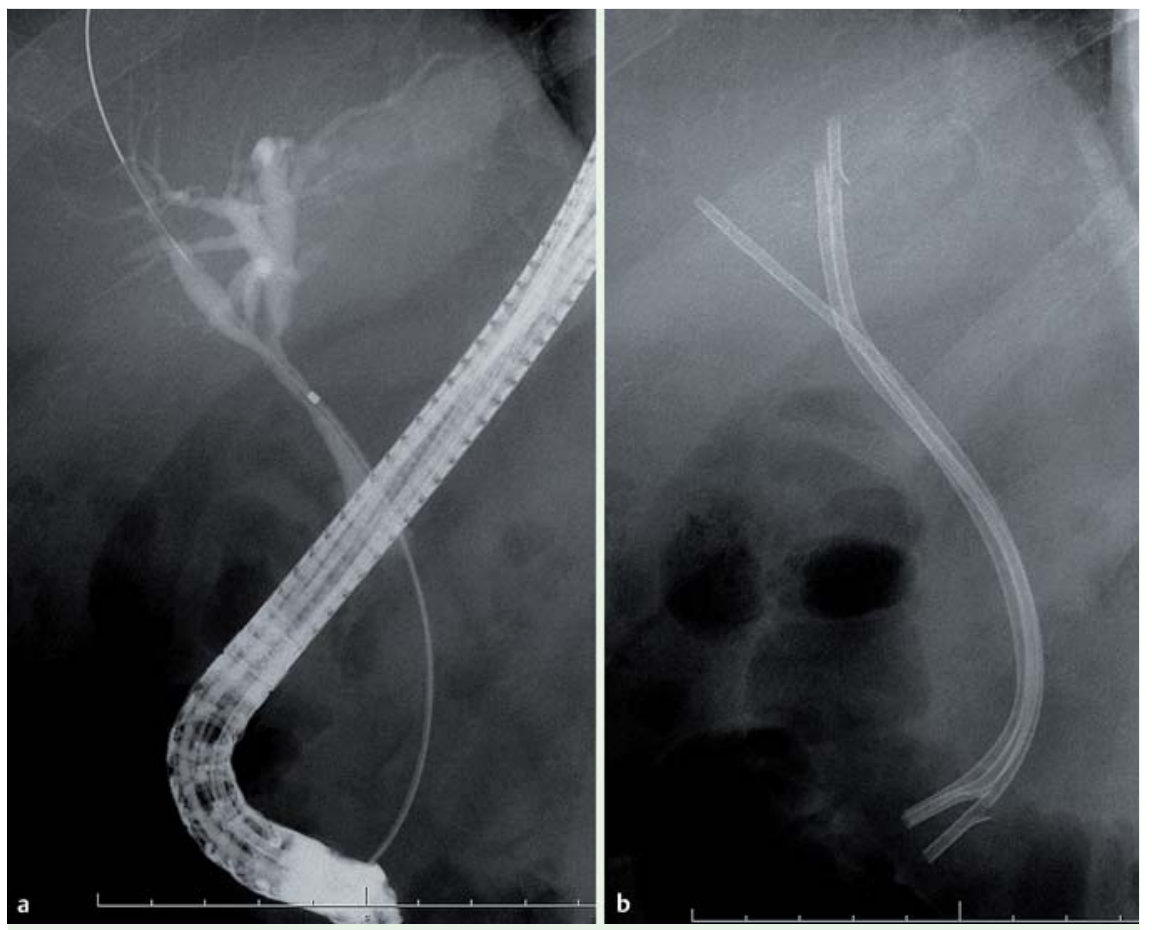

Fig. 4 Radiographic images taken during an endoscopic retrograde cholangiopancreatography (ERCP) performed 5 days after treatment showing: a resolution of the left hepatic bile duct stricture; b the multiple 7-Fr plastic stents that were successfully placed.

\section{H. Kawakami', M. Kuwatani ${ }^{1}$, K. Eto ${ }^{1}$, T. Kudo' ${ }^{1}$, Y. Abe' ${ }^{1}$, S. Kawahata', \\ M. Kato ${ }^{2}$}

1 Department of Gastroenterology, Hokkaido University Graduate School of Medicine, Sapporo, Japan

${ }^{2}$ Division of Endoscopy, Hokkaido

University Hospital, Sapporo, Japan

\section{References}

1 François E, Kahaleh M, Giovannini $M$ et al. EUS-guided pancreaticogastrostomy. Gastrointest Endosc 2002; 56: 128-133

2 Hookey LC, Debroux S, Delhaye M et al. Endoscopic drainage of pancreatic-fluid collections in 116 patients: a comparison of etiologies, drainage techniques, and outcomes. Gastrointest Endosc 2006; 63: 635-643

3 Giovannini M. Therapeutic Endoscopic Ultrasonography in Pancreatic Malignancy. Is the ERCP Passè? JOP 2004; 5: 304-307

4 Kwan V, Eisendrath P, Antaki $F$ et al. EUSguided cholecystenterostomy: a new technique (with videos). Gastrointest Endosc 2007; 66: $582-586$

5 Súbtil JC, Betes M, Muñoz-Navas M. Gallbladder drainage guided by endoscopic ultrasound. World J Gastrointest Endosc 2010; 2: 203-209

\section{Bibliography}

DOI http://dx.doi.org/

10.1055/s-0031-1291675

Endoscopy 2012; 44: E119-E120

(c) Georg Thieme Verlag KG

Stuttgart · New York

ISSN 0013-726X

\section{Corresponding author}

\section{H. Kawakami, MD PhD}

Department of Gastroenterology

Hokkaido University Graduate School of Medicine Kita 15, Nishi 7, Kita-ku

Sapporo 060-8638

Japan

Fax: +81-11-7067867

hiropon@med.hokudai.ac.jp 